\title{
Place Rank: Valuing Spatial Interactions
}

\author{
Ahmed El-Geneidy • David Levinson
}

(C) Springer Science+Business Media, LLC 2011

\begin{abstract}
Accessibility measures the potential of opportunities for interaction. This paper proposes and explores a new flow-based measure, "place rank" using origin-destination information. Both impedance and value of opportunities are embedded in the dataset that includes the origin and destination of each person within the studied region. Individuals contribute to the place rank at their destination (work) zone with a power that depends on the attractiveness of the zone of origin. In this paper we demonstrate this place rank measure for three activities (Jobs, Resident Workers, and Health Services) in the Minneapolis-St. Paul metropolitan region and Jobs in Montréal, Canada. We compare place rank to traditional measures of accessibility. Since place rank is based on actual choices of origins and destinations it is a measure of realized rather than potential opportunities, and so unlike accessibility measures. Also it does not require the knowledge of travel time between all origins and destinations.
\end{abstract}

Keywords Accessibility - Mobility - Gravity based • Cumulative opportunity • Land use $\cdot$ Place rank $\cdot$ PageRank

\footnotetext{
A. El-Geneidy

School of Urban Planning, McGill University, Montréal, Canada

e-mail: ahmed.elgeneidy@mcgill.ca

URL: http://tram.mcgill.ca/index.html

D. Levinson $(\bowtie)$

Department of Civil Engineering, University of Minnesota, Minneapolis, MN, USA

e-mail: dlevinson@umn.edu

URL: http://nexus.umn.edu
} 


\section{Introduction}

Transportation practice aims to move people and goods safely and efficiently. The barometers used to measure efficiency attributes include hours of delay, speed of traffic, and number of cars in congestion. These statistics have become standard performance measures used to compare conditions within cities, and regions within cities, over time. Newspapers around the United States wait eagerly for the well-known annual rankings from the Texas Transportation Institute (Schrank and Lomax 2005) to relay to their residents how well (or in a perverse sense of pride, how poorly) their city is performing. Similarly various cities around the world generate annual congestion indicators.

Measures of congestion, however, have limited utility. They provide a snapshot of only a select dimension of a city's transportation system: the ability of residents to transport themselves under certain conditions (e.g., free flow travel times). Measures of mobility are merely concerned with the ability to move, but not with where one is going. In many respects, such measures fail to adequately capture other essential dimensions of a city's entire transportation environment - that is, how easy it is to get around.

Land use practice on the other hand deals with controlling the density and arrangement of activities. There are great debates about what constitutes the best arrangement, and there is no clear goal comparable to what underlies transportation engineering practice, rather it is a multi-objective problem (Matthews et al. 2006). However the success of a city is determined by its accessibility, cities with more accessibility are more valuable (in toto and per unit) than those with less accessibility.

Accessibility theory argues transportation systems should aim to help people participate in activities distributed over space and time. Accessibility indicates the performance of how well combined transportation-land use systems serve communities, and is shaped by both land use (Levinson 1998; Scott and Horner 2008) and transportation (Axhausen 2008). The concept of "accessibility" has been coin in the planning field for over five decades. Improving accessibility is a common element in the goals section in many transportation plans in the United States and globally (Handy 2002). However, the term "accessibility" is often misused and confused with other terms such as "mobility".

Mobility measures the ability to move from one place to another. The word accessibility is derived from the words "access" and "ability", thus meaning ability to access, where "access" is the act of approaching something. The word derives from the Latin accedere "to come" or "to arrive." Here we concern ourselves with the ease of reaching valued destinations or activities rather than ease of traveling along the network itself. One of the first definitions of accessibility in the planning field was suggested by Hansen (1959), who defines accessibility as a measure of potential opportunities for interaction. Alternative measures are reviewed in Handy and Niemeier (1997) and Geurs 
and van Wee (2004) and a use-based measure appears in Ottensmann and Lindsey (2008).

This paper, extending El-Geneidy and Levinson (2006), introduces and explores a new flow-based measure: place rank, and compares it to three traditional (destination and travel time-based) accessibility measures (cumulative opportunity, gravity-based, and inverse balancing factor). The differences are several. First, place rank focuses on the implicit value of destinations more than the ease of reach, while other measures value all destinations of a type equally, subject to travel time, or require exogenous ratings. Second place rank directly employs flow data, while other measures use travel time and land use data.

Place rank can be used in cases where only flow data is available. Currently home and work locations are recorded through data collected by labor agencies, (e.g. in the US, the Longitudinal Employment Household Dynamics survey, orchestrated by the US Census), but this data does not include mode or journey time of transport. Several databases are present for market analysis this data include where people shop for certain goods without the knowledge of the mode being used or travel time of the trip. Similarly such data is available through health care providers or health insurance agencies, where the home and place of treatment are known while the mode of transport is also unknown. While other sources can be used to estimate travel time, these estimates are historically not very accurate, and often based on shaky assumptions such as shortest path (Zhu and Levinson 2010). Unlike utility-based measures of accessibility, place rank does not require the presence of a regional travel demand model to compute.

Longitudinal studies conducted over several months show that travel behavior of individuals is largely habitual, identifying fixed activity spaces for individuals (Schoenfelder and Axhausen 2010). Individual activity space contains $90-95 \%$ of all their potential places of interest. This implies that the difference between actual and potential accessibility may not be that great. Accordingly a measure derived from actual activity can be used in understanding this relationship.

The next section defines those measures in turn as well as competition measures. Then the data for the application of these measures are presented, and a comparison of the access under each method is shown across several case studies. Statistical correlations between the various measures are provided. The conclusion summarizes the paper and suggests directions for practice and research.

\section{Defining accessibility}

The literature has described numerous measures of accessibility (Geurs and van Wee 2004; Handy and Niemeier 1997; Iacono et al. 2010; Pirie 1979), several of the most widely known are described in turn. The place rank measure is then introduced. 


\subsection{Cumulative opportunity measure}

The isochronic or cumulative opportunity measure (Vickerman 1974; Wachs and Kumagai 1973) counts the number of potential opportunities that can be reached within a predetermined travel time (or distance).

$$
A_{i}=\sum_{j=1}^{J} X_{j} D_{j}
$$

Where:

$A_{i} \quad$ Accessibility measured at point $i$ to potential activity in zone $j$

$D_{j} \quad$ Destinations in zone $j$

$X_{j} \quad$ A binary value equals to 1 if zone is within the predetermined threshold and 0 otherwise

For instance this measure can be used to identify the number of recreational opportunities around a residential location that are within 400 meters (approximately one quarter mile) of network distance of zone. This measure does not account for the size of the destination (attractiveness) or the impedance of reaching it (cost) beyond a binary decision variable. It is widely used in hedonic modeling to control for access to neighborhood amenities. It is simple to explain and compute, but makes an artificial distinction that opportunities 399 meters away are valuable, while those 401 meters away have no value.

\subsection{Gravity-based measure}

The gravity-based measure discussed in Hansen (1959) is another widely used general method for measuring accessibility.

$$
A_{i}=\sum_{j} D_{j} f\left(C_{i j}\right)
$$

Where

$C_{i j} \quad$ The impedance or cost of travel between $i$ and $j$

$f()$ The impedance function

A variety of impedance functions are found in practice. This measure relies on travel time information (which is often inaccurate), and does not fully use available information about interzonal flows.

\subsection{Competition measures}

Several accessibility measures are generated to account for competition factors. These are generally based on modifications of the gravity measures. A first approach has been to measure accessibility to certain opportunities (jobs) and to individuals (workers) from a given location and then divide one measure by the other (Levinson 1998; Van Wee et al. 2001). This only accounts 
for competition effects at one location, though competition can emerge from anywhere in a region (Geurs and van Eck 2003).

A second approach, applied by Shen (1998) involves incorporating the demand potential (job seekers) to the calculation by dividing the supply (jobs) located in destination zone $\mathrm{j}$ by the demand potential within reach of that zone $\mathrm{j}$. In this model, accessibility equals the ratio of the total number of opportunities to the total number of opportunity seekers in zone $\mathrm{j}$. This model overestimates competition because it accounts for the number of potential job seekers, but not for the impact of jobs in other zones (Geurs and van Eck 2003).

A third approach is the inverse balancing factors of the doubly constrained spatial interaction model (Wilson 1971). In Wilson's interaction model the balancing factors ensure that the magnitude of flow originating from and destined for each zone equals the actual number of activities in the zone.

With this measure the supply and demand potential for all the zones are calculated iteratively, ensuring that the number of trips to and from each zone equal the number of opportunities (Geurs and van Eck 2003). In other words, it calculates all the potential opportunity-seekers $\left(O_{i}\right)$ for the area as well as all the potential opportunities available $\left(D_{j}\right)$ and balances the numbers until the model is stable. Using accessibility to jobs and number of potential job seekers, this model can be explained as:

$$
\begin{aligned}
& A_{i}=\sum_{j=1}^{n} \frac{1}{B_{j}} D_{j} f\left(C_{i j}\right) \\
& B_{j}=\sum_{j=1}^{n} \frac{1}{A_{i}} O_{i} f\left(C_{i j}\right)
\end{aligned}
$$

$A_{i}$ is the accessibility to jobs for people living in location $i$. While, $B_{j}$ accessibility to workers at zone $j . D_{j}$ is the number of destination opportunities (e.g. jobs) in zone $j, O_{i}$ the number of people originating (opportunity seekers) in location $i$, and $f\left(C_{i j}\right)$ the impedance function measuring the spatial separation between $i$ and $j$. This could be stratified by mode, destination type, or other categorization.

The main assumption made in this measure of accessibility is the value of the opportunity. The value is assumed to be equal for all job seekers (subject to travel time) and it depends on the number of opportunities and not their attractiveness, without stratification on the part of the analyst.

All the above-mentioned measures are typically generated for a specific mode. There is a need for a measure of accessibility that is generic enough to incorporate all modes to measure the overall performance of the transportation system. Also there is a need for a measure that can incorporate the value of opportunities based on actual demand and not assumed one. Not all job seekers value the same jobs in the same manner. Place rank addresses this issue. 


\subsection{Place rank}

Our proposed place rank measure is inspired from a methodology developed by Brin and Page (1998) used in ranking web pages for large scale search engines, such as Google, which they founded. A web page gets its power from the links connecting to it, while the power of those links comes mainly from the rank of their original host. In an urban planning context this notion can be used to measure the levels of accessibility at destinations and origins. Knowing actual origins and destinations is a key component in place rank. The place rank of a zone is determined based on the number of people commuting to this zone to reach an opportunity. The power of the contribution of this person depends on the attractiveness of the zone of origin. Place rank does not require an impedance function, since the impedance function is already embedded in the flow data. People are already taking the trip and bypassing other potential destinations to reach their desired destination due to its value. The mathematical formulation of the model is as follows:

$$
\begin{gathered}
P_{i, t}=\frac{R_{i, t}}{O_{i}} \\
E_{i j, t}=E_{i j, t-1} * P_{i, t-1} \\
R_{j, t}=\sum_{i=1}^{I} E_{i j, t} \\
R_{i, t}=R_{j, t}^{T} \\
\text { If } R_{i, t}=R_{i, t-1}, \text { stop; Else (Eq. (5)). }
\end{gathered}
$$

Where:

$R_{j, t} \quad$ The place rank (weighted number of people destined) for zone $j$ in iteration $t, R_{j, 0}=\sum_{i} E_{i j, 0}$

$P_{i, t} \quad$ The power of each person leaving $i$ in iteration $t ; P_{i, t}=P_{j, t}^{T}$

$I \quad$ The total number of $i$ zones

$E_{i j, t} \quad$ The weighted trip table, the weighted number of people leaving $i$ to reach an activity in $j, E_{i j, 0}$ is the original trip table

$O_{i} \quad$ The number of people originating in zone $i ; O_{i}=\sum_{j} E_{i j, 0}$

Place rank redistributes the total number of people involved in the studied activity between the zones in a manner that is weighted based on the zones' attraction and the power of the links. The calculations are processed for each zone for at least two iterations. The place rank is determined when the difference between each two consecutive ranking calculations equals zero (with some arbitrary degree of precision), meaning the model reaches equilibrium. A mathematical example explains the method. Figure 1 displays the hypothetical zone structure and zone to zone flows used in the example. 


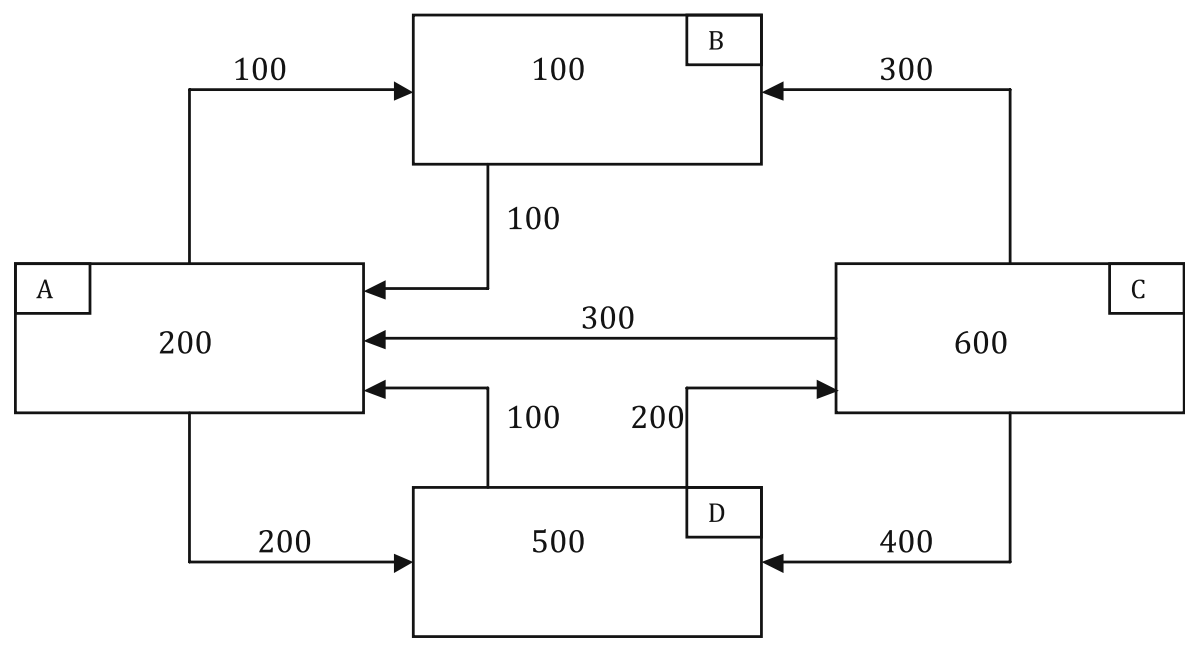

Fig. 1 Place rank mathematical example—spatial illustration of flows

Each zone can be considered a place (e.g. transportation analysis zone (TAZ) or a city or a township) where people might live and work. Accordingly it is important that each zone will be used as both as an origin and as a destination.

In this example we use 4 zones: $A, B, C$, and $D$. Zone $A$ has a total of 500 workers residing in it. Only 200 of these workers stay in $A$ for jobs, while 100 workers leave zone $A$ to reach a job opportunity at $B$ and 200 workers leave $A$ to reach an opportunity in $D$. $A$ is a major employment attraction which attracts 700 workers from all zones. Of these, 200 come from $A$ itself, another 100 come from $B, 300$ come from $C$ and another 100 come from $D$. Meanwhile Zone $B$ has 200 workers and 500 job opportunities. Similarly $C$ and $D$ respectively have 1,600 and 800 resident workers and 800 and 1,100 job opportunities.

A person leaving zone $A$ to work in any zone will contribute 1.4 to the zone in which he is going, we say that a resident worker of $A$ has a power of 1.4. This number is derived by dividing the total job opportunities in $A$ by the total number of workers residing in $A$. For Zone $B$ the power for a worker leaving

Table 1 Example 1: Calculating place rank original data

\begin{tabular}{lrrrrr}
\hline & $A$ & $B$ & $C$ & $D$ & $\begin{array}{r}\text { Total workers } \\
\text { by origin }\left(O_{i}\right)\end{array}$ \\
\hline$A$ & 200 & 100 & 0 & 200 & 500 \\
$B$ & 100 & 100 & 0 & 0 & 200 \\
$C$ & 300 & 300 & 600 & 400 & 1,600 \\
$D$ & 100 & 0 & 200 & 500 & 800 \\
Total jobs by destination $\left(R_{j, 0}\right)$ & 700 & 500 & 800 & 1,100 & 3,100 \\
Total workers by origin $\left(O_{j}=O_{i}^{T}\right)$ & 500 & 200 & 1,600 & 800 & \\
Power of a single link $\left(\frac{R_{j, 0}}{O_{j}}=P_{j, 0}\right)$ & 1.4 & 2.5 & 0.5 & 1.37 & \\
\hline
\end{tabular}


Table 2 Example 1: Calculating place rank first iteration

\begin{tabular}{lcrrrr}
\hline & $A$ & $B$ & $C$ & $D$ & $\begin{array}{r}\text { Total workers } \\
\text { by origin }\left(O_{i}\right)\end{array}$ \\
\hline$A$ & 280 & 140 & 0 & 280 & 500 \\
$B$ & 250 & 250 & 0 & 0 & 200 \\
$C$ & 150 & 150 & 300 & 200 & 1,600 \\
$D$ & 137.5 & 0 & 275 & 687.5 & 800 \\
Interim place rank & 817.5 & 540 & 575 & $1,167.5$ & 3,100 \\
$\quad$ (weighted destinations) $\left(R_{j, 1}\right)$ & & & & & \\
Total workers by origin $\left(O_{j}=O_{i}^{T}\right)$ & 500 & 200 & 1,600 & 800 & \\
Power of a single link $\left(\frac{R_{j, 1}}{O_{j}}=P_{j, 1}\right)$ & 1.63 & 2.7 & 0.36 & 1.45 & \\
\hline
\end{tabular}

this zone is even higher, 2.5, which is based on the same ratio. A worker leaving zone $B$ is more valuable than any other worker leaving other zones due to the number of opportunities at $B$ compared to the number resident workers at $B$.

Table 1 summarizes the origins and destinations matrix with the power of each link or person leaving the zone, while Table 2 includes the output of the first iteration of the measure. The original number of workers who reside in a zone is multiplied by the power of each link to form the new matrix displayed in Table 2.

The weighted sum of the jobs by destination is the current rank of the zones. This rank is used again to generate a new link power $\left(P_{i 2}\right)$. The new link power is then multiplied by the original matrix to form a third weighted origindestination matrix. The third matrix is then compared to the second to check if the values in the third matrix stabilized (the difference between values in the third and second matrix equal zero). The process is repeated. Stability obtains after 19 iterations for the above example. The final place rank of each zone equals the sum of jobs at the destinations in the weighted format. The ranking of each zone is shown in Table 3.

The approach of using ranking systems in urban planning context is relatively new and has started to show its advantages in other studies related to travel behavior. For example Jiang (2009) uses PageRank to rank individual space and travel behavior, and finds that the PageRank scores are more correlated to human movement rates than space syntax metrics. In our case we use it to enhance the existing practice of measuring accessibility.

This place rank measure works only when there are both jobs and residents in a geographic region (otherwise the power of a zone is zero or infinity). Traffic zones are often homogenous, with either many jobs and few or no

Table 3 Final place rank, after 19 iterations, $\left(R_{j, 19}\right)$ for Example 1

\begin{tabular}{lc}
\hline Zone & Place rank \\
\hline$A$ & 848.25 \\
$B$ & 524.37 \\
$C$ & 493.53 \\
$D$ & $1,233.83$ \\
Total & 3,100 \\
\hline
\end{tabular}


houses, or many houses and few or no jobs. Thus they cannot be used in placerank measure that requires both incoming and outgoing trips. One needs to look at an area heterogeneous enough to include both jobs and houses. Minor Civil Divisions (MCD) (cities, towns, and townships) in the Twin Cities metropolitan area are one such geography. Alternatively, one could develop a more complex method to determine power (such as using a traditional accessibility measure, which will generally be non-zero for small geographical areas), which is not pursued here.

Place rank can be forecasted only if expectations of future flows are available, e.g. using traditional transportation forecasting methods. In our view, the advantage of this measure is to help in prioritizing decisions and policies based on a clear image of the present.

\section{Case 1: Journey to work in the twin cities: place rank vs. gravity and competing opportunities}

Implementing place rank requires knowledge of flows between origins and destinations. There are several data sources where origin and destination of each individual in a region is readily available. The Longitudinal Employer-
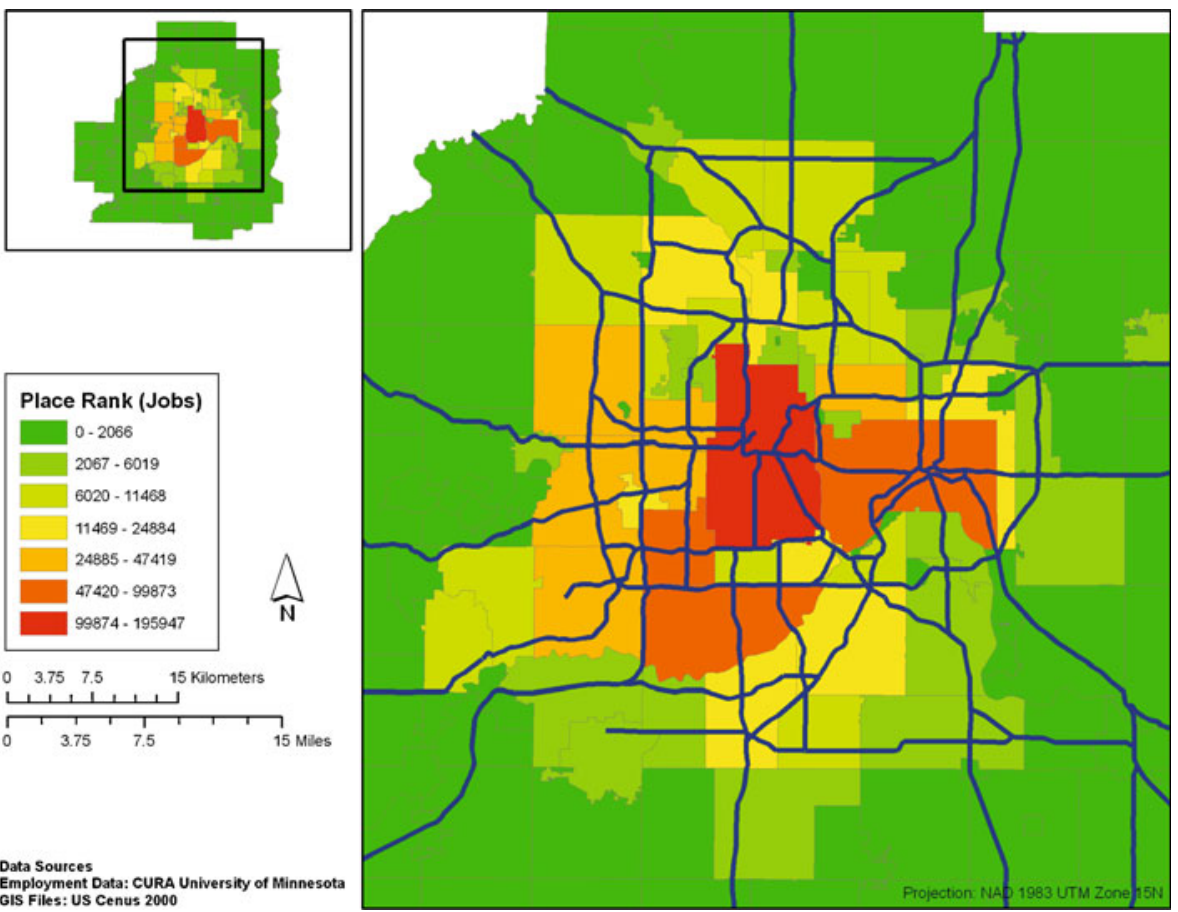

Data Sources
Employment Data: CURA University of Minnesota Employment Data: CURA
GIS Files: US Cenus 2000
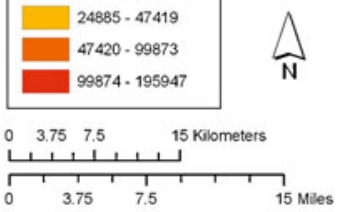

Fig. 2 Place rank for jobs 
Household Dynamics dataset (LEHD) is one such dataset (LEHD 2003). The LEHD is a comprehensive dataset that includes for each individual a place of residence (origin) and an employment location (destination) both identified at the Census Block level of analysis. The major disadvantage of this dataset is the absence of travel time to generate accessibility measures, while its main advantage is its availability across almost all of the US.

Measuring accessibility using cumulative opportunity and gravity-based measures requires knowledge of levels of attractions at destinations and impedances between those destinations. Impedance can be presented as either distance or travel time or cost between origins and destinations. Travel time is one of the most commonly used functions in the transportation literature. For our analysis automobile travel time is obtained at the TAZ-to-TAZ level of analysis from the transportation planning model of the Metropolitan Council which is the regional planning agency serving the Twin Cities seven-county metropolitan area. Travel time is available for both congested and uncongested time periods (Filipi 2005). All the data used in this paper is aggregated to the Minor Civil Division (MCD) level of analysis to ensure consistency in the level of analysis among the various measures.

Place rank was calculated for jobs in the Twin Cities region using the LEHD data at the MCD level of analysis. Around 300 iterations were needed to reach stability for this analysis. Figure 2 shows the output.
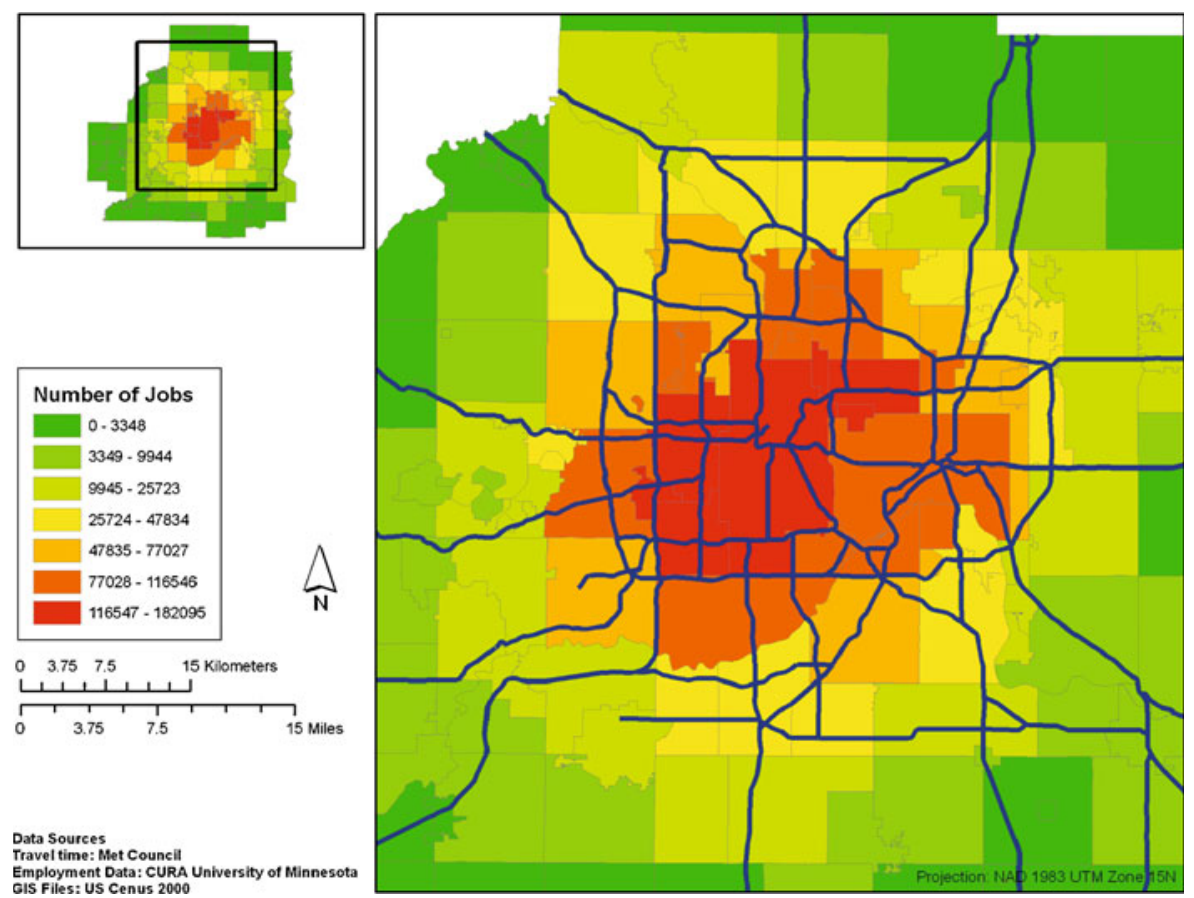

Dravel time: Met Council

Employment Data: CURA University of Minnesota GIS Files: US Cenus 2000

Fig. 3 Cumulative opportunity (number of jobs in $10 \mathrm{~min}$ by auto in 2000) 
It is clear from the figure that concentration of jobs in the heart of the metropolitan region (the City of Minneapolis) has the highest ranking, while the cities of Saint Paul (east of Minneapolis), Edina (west), and Bloomington (south) fall in the second category. These three cities include major headquarters and office buildings, and shopping facilities such as the Mall of America. Meanwhile areas in between these cities exhibited a lower ranking due to fewer jobs. For example a person residing in the city of Minneapolis (the center of the map) and working in the suburbs adds more to the ranking of the zone where he is working than someone living in the suburbs and working downtown. The reason the city of Minneapolis achieves its high rank, is not only due to the number of workers attracted to the job opportunities in the city, it is also due to the strength of the origins where these workers reside.

Comparing place rank to accessibility measures is an essential step. Figure 3 shows the cumulative opportunity accessibility measure showing the number of jobs within $10 \mathrm{~min}$ of travel time from the origin. This was obtained by aggregating data from the TAZ level of analysis to the MCD level for comparison purposes. Figure 4 shows the gravity-based accessibility measure to jobs. Comparing these maps to Fig. 2 it is clear that though the three measures, while similar are not identical. From a statistical standpoint, a correlation matrix can be generated to compare the three measures.
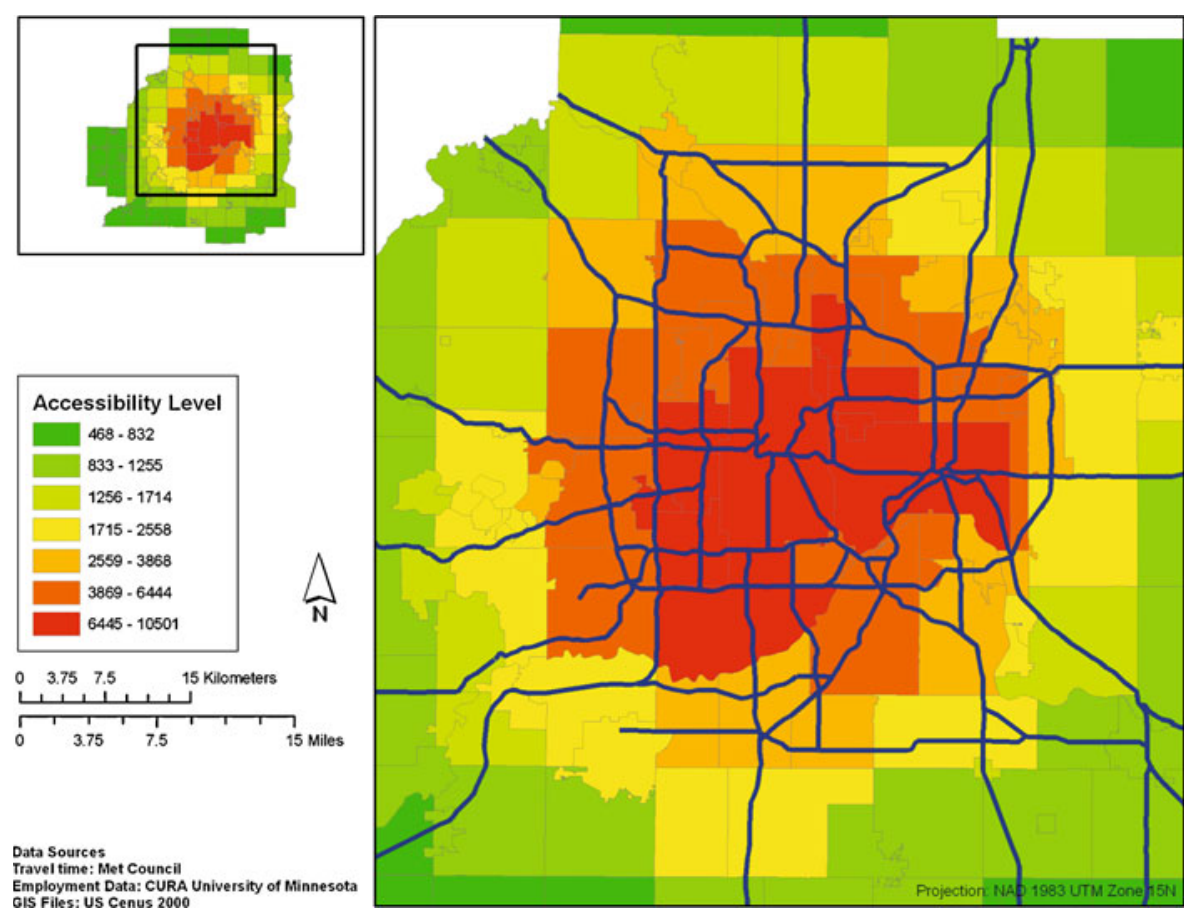

Travel time: Met Council

Employment Data: CURA University of Minnesota GIS Files: US Cenus 2000

Fig. 4 Gravity-based accessibility measure to jobs by auto in 2000 using $1 / t^{2}$ impedance function 
Table 4 Correlation matrix for place rank and gravity-based accessibility measures

\begin{tabular}{llllll}
\hline & Place rank & & Gravity-based accessibility \\
& $\begin{array}{l}\text { To resident } \\
\text { workers }\end{array}$ & To jobs & & To jobs $\begin{array}{l}\text { To resident } \\
\text { workers }\end{array}$ \\
\hline Place rank to resident workers & 1 & & & & \\
Place rank to jobs & 0.752 & 1 & & \\
Gravity-based to jobs & 0.431 & 0.572 & & 1 & \\
Gravity-based to resident workers & 0.425 & 0.415 & & 0.944 & 1 \\
\hline
\end{tabular}

The Pearson's correlation measure is shown in Table 4. The gravity-based measures are internally highly correlated $(0.95)$, as are the place rank measures (0.75). The measures are positively, but less strongly correlated to each other (0.4-0.6). Figure 5 shows the level of correlation between the gravity and place rank measures for jobs and resident workers to various cumulative opportunity measures. The cumulative opportunity measure is calculated either based on the number of jobs or resident workers that can be reached within 10, 15, 20, $30,40,45,50$ and $60 \mathrm{~min}$. of travel time. The gravity-based method is highly correlated to the cumulative accessibility measure at the 10,15, 20 and $30 \mathrm{~min}$. bins. This relation tends to decline with the increase in the travel time bin (40, 45, 50 and 60). Place rank is positively, but less strongly correlated with the cumulative opportunity measure than the gravity method. In addition a decline in the level of correlation is present at the higher level bins (40, 45, 50 and 60). The same phenomenon is present for the resident workers place rank measure.

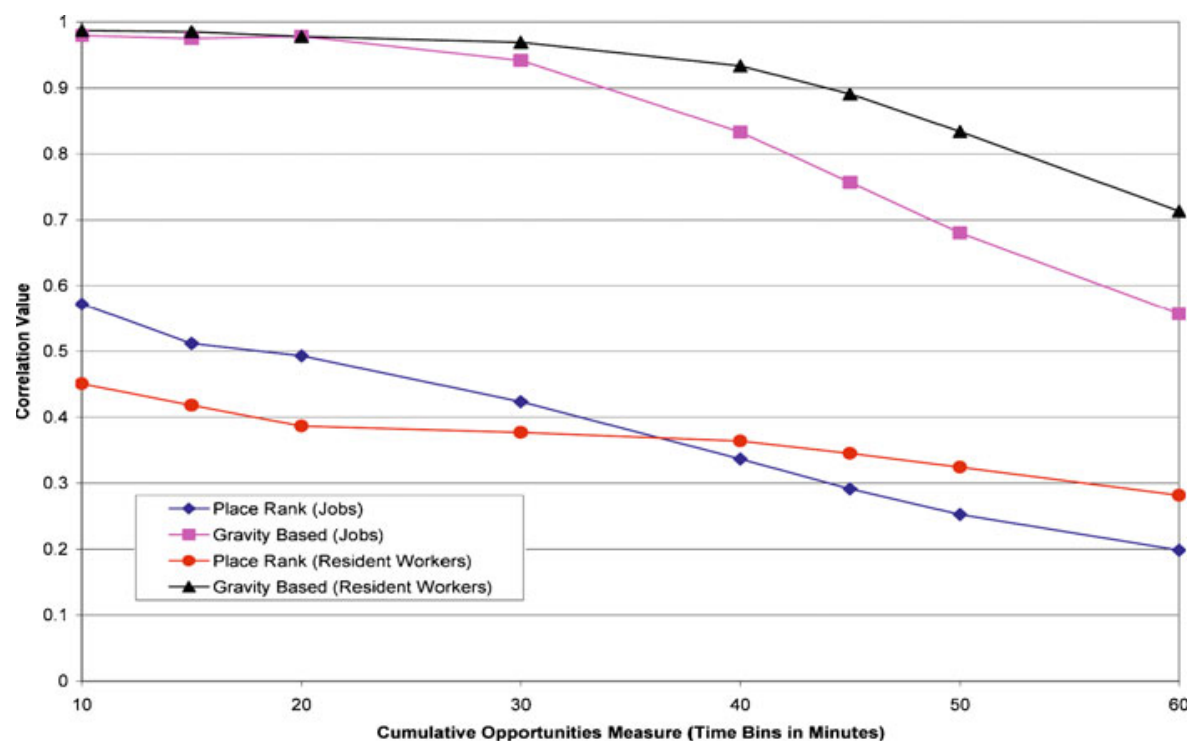

Fig. 5 Cumulative opportunities correlated to other measures of accessibility 


\section{Case 2: Journey to work in Montréal: place rank vs. inverse balancing factor}

Figure 6 consists of two maps for the Montréal, Quebec, Canada metropolitan region comparing the inverse balancing factor of the doubly constrained spatial interaction model and the place rank. The figure also includes a correlation matrix between several measures of accessibility to jobs including gravity and cumulative opportunity. The travel time used in this analysis is obtained from a travel demand model generated by the Ministry of Transport of Quebec (MTQ). The number of jobs is obtained from the Canadian Census. The impedance factors used in generating the gravity and the inverse balancing factor are obtained from travel time decay curves generated from the Montréal Origin-Destination survey (Agence métropolitaine de transport 2003). The inverse balancing factor was derived from a gravity based measure of accessibility to jobs and to workers through a simple program designed in Microsoft Access.

As of 2008, the census metropolitan area of Montréal comprises 3.8 million inhabitants (Statistics Canada 2009). The city of Montréal is located on the Island of Montréal, occupying $364 \mathrm{~km}^{2}$ of the Island's $504 \mathrm{~km}^{2}\left(141 \mathrm{mi}^{2}\right.$ of $195 \mathrm{mi}^{2}$ ) and grouping 87 percent of the Island's population (Communauté
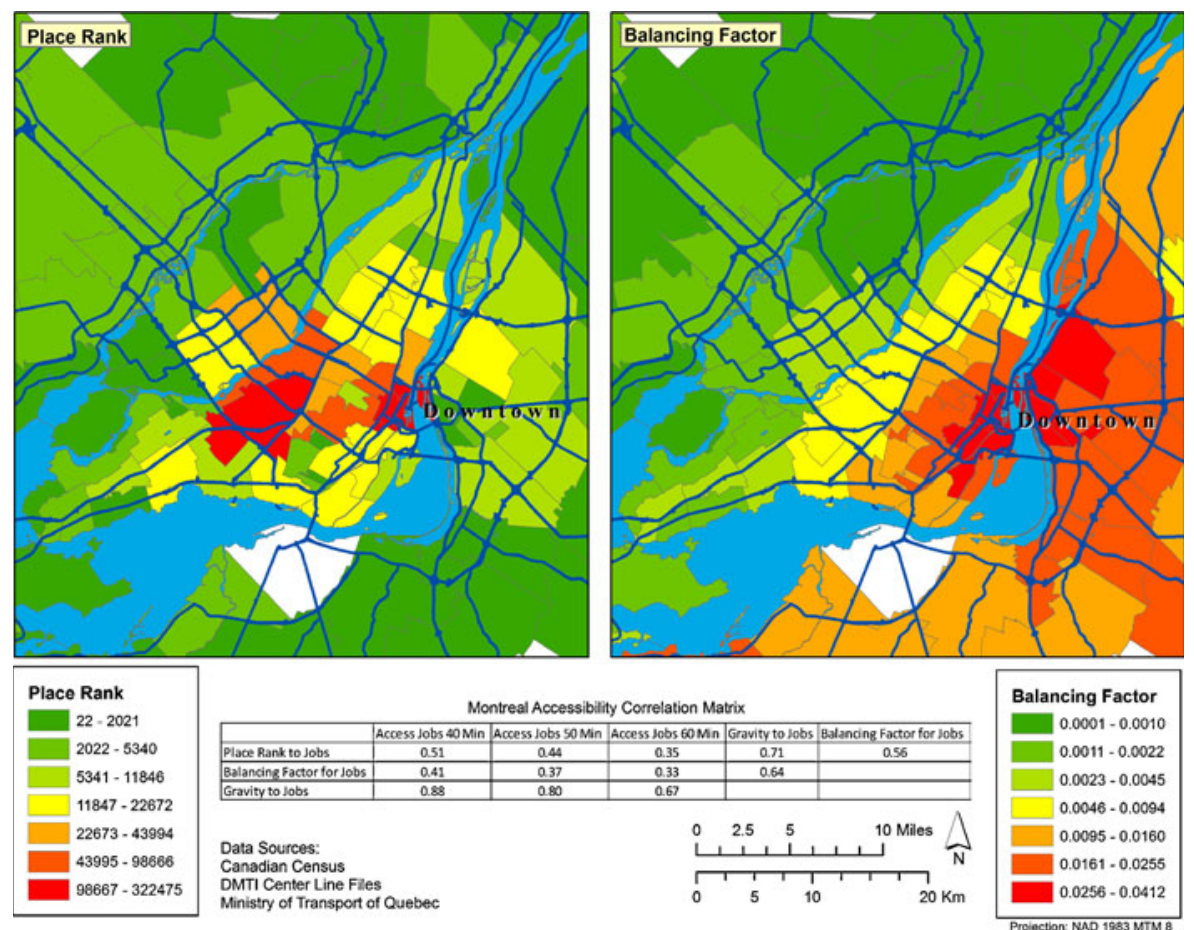

Montreal Accessibility Correlation Matrix

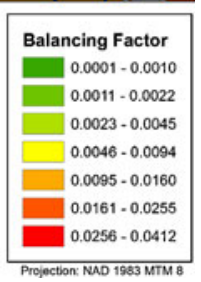

Fig. 6 Montréal, Quebec Canada comparison 
métropolitaine de Montréal 2008). A particular geographic feature of the region is the presence of Mount Royal west of the CBD, an obstacle that can only be crossed by one collector road or one commuter train line. In terms of demographic weight, the centre of the region is strong with 1.6 million people living in the city of Montréal. According to Coffey an Shearmur (2001), Montréal is a polycentric city, where six specialized employment centers exists other than the CBD, although they are all close to the center.

Place Rank correlates with other measures of accessibility. The results of place rank are correlated to inverse balancing factor $(0.56)$, gravity $(0.71)$, and cumulative opportunities (0.3-0.6). This finding corroborates the results above from the Twin Cities analysis concentrating on accessibility to jobs.

\section{Case 3: Health care in the twin cities}

To illustrate another context, data obtained from major health providers is used to generate place rank for health services. This data obtained from health care providers identifies the home address of each individual visiting a health care facility. Through minor GIS work this data can be aggregated to the
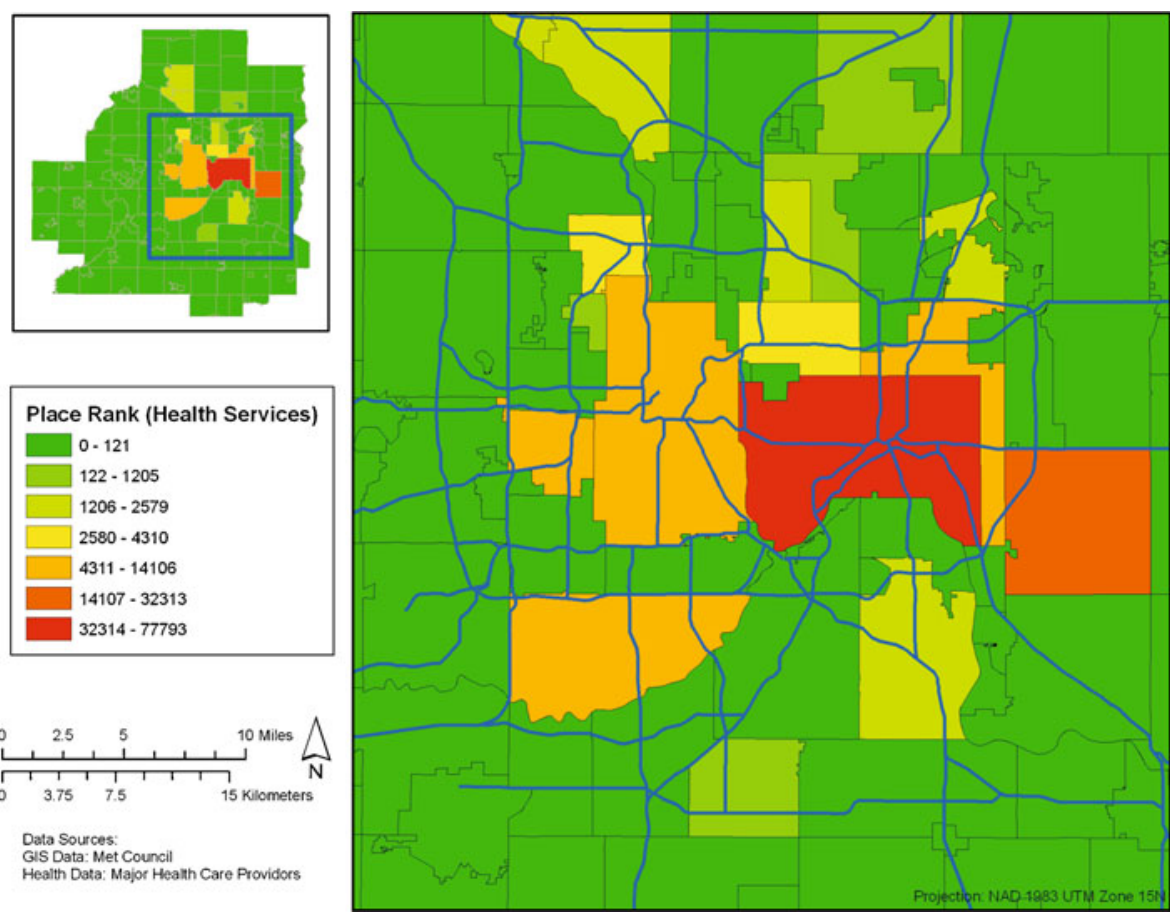

Place Rank (Health Services)

$0-121$

ए $122-1205$

$\square 1206-2579$

$\square 2580-4310$

$4311-14106$

$14107 \cdot 32313$

$32314-77793$

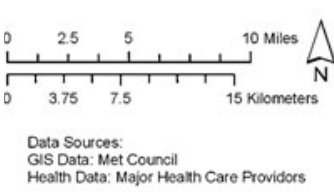

Fig. 7 Place rank for health services 
census block level to ensure anonymity in the identity of each individual. Such data can be available through partnerships with health care providers.

Place rank to health services in the Twin Cities region is demonstrated in Fig. 7. The generation of this measure required 74 iterations for the model to reach equilibrium. It is important to note that the shown measure only reflects place rank for health care providers who agreed to share their data with our research team and cannot be used for generalizations or for identifying gaps in health care services. In order to do so a complete dataset from all health care providers in the region is required.

\section{Conclusion}

Place rank is a new, flow-based measure that accounts for the number of opportunities that an individual foregoes in a zone to take an opportunity in another zone. Unlike the impedance function that is used in traditional gravity-based accessibility measures, which is derived from an actual, though often incomplete, origin and destination matrix, the impedance function is already embedded in the place rank calculations, which depend directly on the flows between places. Place rank, unlike aggregate measures of accessibility, does not assume a uniform level of attractiveness of jobs (subject to location) without taking into account how many people are attracted to these jobs and the kind of other jobs they are leaving to get to this one.

This measure has the advantage that travel time is not needed and accordingly no estimates are incorporated in the analysis, which comes at the cost of additional computational complexity. Similar to competition measures of accessibility, such as the inverse balancing factor, place rank is iterative (and thus requires implementing an algorithm in software).

The data used in place rank can be obtained from various sources directly, for example in this study, data was provided by the U.S. Census Bureau, Canadian Census and through partnership with health care providers. Also place rank for various purposes can be generated based on comprehensive origin destination surveys that accurately sample the region.

In practice, place rank can be applied to any major activity with available data. The level of correlation between the place rank measure and conventional measures of accessibility emphasize the findings made by Schoenfelder and Axhausen (2010) that the difference between actual and potential accessibility is not great. Compared to classical measures of accessibility, place rank is not mode specific, and can be estimated either for a single or multiple modes, depending on the availability of flow data by mode, enabling comparisons across modes.

The major disadvantage is a scaling issue, place rank only applies to areas that have the same kind of information at origins and destinations (e.g. number of jobs). In this paper we used city/borough as our main unit of analysis to ensure the presence of origins and destinations in each unit of analysis. However use of a different measure (e.g. job accessibility rather than jobs 
themselves) could eliminate this disadvantage. Further work is needed to determine the appropriate unit of spatial analysis that can be used to generate this measure.

Place rank highlights the most and least attractive zones so planners and engineers can prioritize land use and transportation improvements in the studied region to maximize the benefits to existing users or to ensure equity by directing planning efforts towards low ranked zones. Therefore we believe place rank complements, rather than competes with, existing accessibility measures to help understand land use and transportation interactions through ranking the attractiveness of zones in a region.

In this article we have explored the merits of place rank through comparing it to widely used measures of accessibility. Our expectations in the future is that place rank will complement existing measures of accessibility, providing a measure that has fewer assumptions and relies instead on observed O-D flow data.

Acknowledgements This work was funded by the Minnesota Department of Transportation as part of the Access to Destinations project. The authors would like to thank Mark Filipi, Transportation Forecast/Analyst at the Metropolitan Council, for providing the travel time matrix and other data used in the study. Also thanks are given to Kris Nelson and Jeffrey Matson for providing the LEHD data used in the analysis. The authors would like to thank Assumpta Cerda for her help in generating the Montréal measures. Also thanks should be given to Mr. Pierre Tremblay from MTQ who provided the travel time data. Thanks to Daniel Bergeron from the AMT for providing the Montréal OD survey used in generating the impedance factors for gravity and inverse balancing factor measures for the Montréal case study. The Montréal case study was part of a bigger project funded by the Ministry of Transport of Quebec. The authors would like to especially thank Mohamed Mokbel, Assistant Professor Computer Science Department, University of Minnesota for his help in programming the place rank measure. Finally, the authors would like to thank Aura Reggiani, Juan Carlos Martin, and the anonymous reviewers for comments on earlier drafts of this paper.

\section{References}

Agence métropolitaine de transport (2003) Enquête origine-destination. Technical report

Axhausen K (2008) Accessibility: long term perspectives. J transp. land use 1(2):5-22

Brin S, Page L (1998) The anatomy of a large-scale hypertextual web search engine. Comput Networks 30(1-7):107-117

Coffey W, Shearmur R (2001) The identification of employment centres in Canadian metropolitan areas: the example of Montreal, 1996. Canadian Geographer/Le Géographe canadien, vol 45. Wiley Online Library, pp 371-386

Communauté métropolitaine de Montréal (2008) Les municipalités en chiffres. http://www. cmm.qc.ca/index.php?id=267. Accessed October 2010

El-Geneidy A, Levinson D (2006) Access to destinations: development of accessibility measures. Technical report

Filipi M (2005) Travel time for the twin cities region. Electrnic database of the Twin Cities travel demand model.

Geurs K, van Eck J (2003) Evaluation of accessibility impacts of land-use scenarios: the implications of job competition, land-use, and infrastructure developments for the Netherlands. Environ Plann B Plann Des 30(1):69-87

Geurs K, van Wee B (2004) Accessibility evaluation of land-use and transport strategies: review and research directions. J Transp Geogr 12(2):127-140 
Handy S (2002) Accessibility- vs. mobility-enhancing strategies for addressing automobile dependence in the US. paper presented at the European Conference of Ministers of Transport May 2002

Handy S, Niemeier DA (1997) Measuring accessibility: an exploration of issues and alternatives. Environ Plann A 29(7):1175-1194

Hansen W (1959) How accessibility shape land use. J Am Inst Plann 25(2):73-76

Iacono M, Krizek K, El-Geneidy A (2010) Measuring non-motorized accessibility: issues, alternatives, and execution. J Transp Geogr 18(1):133-140

Jiang B (2009) Ranking spaces for predicting human movement in an urban environment. Int J Geogr Inf Sci 23:823-837

LEHD (2003) Longitudinal employer household dynamics. Technical report, US Census Bureau, LEHD Program, Suitland, MD

Levinson D (1998) Accessibility and the journey to work. J Transp Geogr 6(1):11-21

Matthews K, Buchan K, Sibbald A, Craw, S (2006) Combining deliberative and computer-based methods for multi-objective land-use planning. Agric Syst 87(1):18-37

Ottensmann J, Lindsey G (2008) A use-based measure of accessibility to linear features to predict urban trail use. J transp. land use 1(1):41-63

Pirie G (1979) Measuring accessibility: a review and proposal. Environ Plann A 11(3):299-312

Schoenfelder S, Axhausen K (2010) Urban rhythms and travel behaviour: spatial and temporal phenomena of daily travel. Ashgate Publishing Company

Schrank D, Lomax T (2005) The 2005 urban mobility report. Technical report, Texas Transportation Institute

Scott D, Horner M (2008) The role of urban form in shaping access to opportunities. J transp. land use 1(2):89-119

Shen Q (1998) Location characteristics of inner-city neighborhoods and employment accessibility of low-wage workers. Environ Plann B Plann Des 25(3):345-365

Statistics Canada (2009) Population of census metropolitan areas (2006 Census boundaries). http://www40.statcan.ca/101/cst01/demo05a-eng.htm. Accessed October 2010

Van Wee B, Hagoort M, Annema J (2001) Accessibility measures with competition. J Transp Geogr 9(3):199-208

Vickerman RW (1974) Accessibility, attraction and potential: a review of some concepts and their use in determining mobility. Environ Plann A 6:675-691

Wachs M, Kumagai T (1973) Physical accessibility as a social indicator. Socioecon Plan Sc 7:327456

Wilson A (1971) A family of spatial interaction models, and associated developments. Environ Plan 3(1):1-32

Zhu S, Levinson D (2010) People don't take the shortest path. Working Papers, Nexus Research Group, University of Minnesota 